\title{
The Configuration of our \\ Horizon of Experience and Judgment as a \\ Dynamic Process. \\ Some considerations about \\ the Laboratory of Consciousness in Hegel's \\ Phenomenology of Spirit
}

\author{
JOSÉ DE JESÚS JAIME GALVÁN \\ State University of New York
}

The aim of this contribution is to point at three ideas that the moment Consciousness of Hegel's Phenomenology of Spirit can lead us to consider: first, that technological innovations or improvements are simply the "outer" response of a deep change in our horizon of experience and judgment. Second, this horizon is essentially in a constant and dynamic process of change. Finally, that the energy that drives any form of technological change abides precisely in the core of human consciousness, the root of any dialectical motion, and every act of revolution finds there its fundamental origin.

It is to be acknowledged that a new encounter with Hegel's text occurred while searching for resources in making explicit the force and processes that drive and direct the development of instruments implicated in experimental science in the XIX ${ }^{\text {th }}$ Century. This does not mean that the publication of the Phenomenology constituted a determinant factor in the consolidation of experimental science after the XIX Century. It was neither the only text, nor the most explicit, that attempted to explain the reasons of such development. Nevertheless, it owes its exceptional character, besides its power to inspire, to its capacity to locate this process within a frame where its meaning and sense shine with particular eminence. Far beyond the implications in the improvement of scientific instruments and research resources, it leads our attention towards the expansive energy of human spirit beneath the multiple endeavors involved in the search to understand the universe and itself, the universe within itself and itself in the universe. That is, modifications of instruments for scientific observation, or any device that mediates and expands our experience, indicate 
not only a qualitative transformation of our own horizon of experience, but also a further step, even if minimum, towards the conquest of the knowledge of our own self.

It has been widely discussed that, in the moment Consciousness of the Phenomenology of Spirit ${ }^{l}$, Hegel claims that a static conception of the idea of substance does not permit us to grasp nor to explain in a satisfactory way the dynamic character of the universe we inhabit, and much less to understand the task of human mind in solving it. There is still much to say on that basis concerning the construction of our own horizon of judgment from which we solve precisely that dynamic world we live in; it leads us to think the configuration of subjectivity within a particular rate of dynamism. This is relevant, for instance in the ambit of education in general, because the desirable point of departure should be that any world-view, any perspective of reality, cannot be established, at a certain moment, once and for all. To affirm such a thing, in any case, when we are twenty five or fifty years old, is as much as to say that we are sitting down comfortably in an error.

The character of the interaction mind-reality could be properly illustrated as a highly dynamic scientific laboratory. The phenomenon of instrumental science, precisely the one Hegel knew in a very important moment of early development, can be reflected in the labor of Spirit as described in Consciousness. The movement of Spirit concretely as expressed between Sense-Certainty and Perception, and Force and The Understanding can constitute a powerful image concerning the co-shaping relationship between our experience of the world and the instruments that mediate such experience; Hegel did not meant that, for sure, but this text certainly can direct our attention to this ambit.

This instrumental mediation surrounds us permanently, through an enormous variety of technological instruments, and technology here does not mean strictly some electronic device, that are constantly subjected to change, a times even radical. Sometimes changes take place not in the structural configuration of things but in their assigned task: we put the chair in front of a door to keep it open when the wind blows. It is clear that in the case of scientific instruments involved in making "visual" hard-to-access phenomena things are not that simple; but, independently of the complexity of the device in question, it is not possible to fully understand such change by looking only at the different elements involved as if they were independent realms: our deep objective or aim, our sensible experience, our theories about the universe, the instruments and their different components, and so forth. The reason for seeing what we

1 An excellent exposition can be found in Ken Westphal's contribution published in the Blackwell Guide to Hegel's Phenomenology of Spirit (WESTPHAL, Ken.Ed. Blackwell Guide to Hegel's Phenomenology of Spirit. Wiley-Blackwell, Malden-Oxford/USA-UK 2009, 325pp). 
see does not abide in the instruments only, and the instruments' shapes and functions are not determined only by our own desire to see or do something; it is a process of co-determination. Nevertheless, all the factors involved seem to be deeply connected within a dynamic process that transcends their singularity. Hegel's discourse in Consciousness notably contributes to review any possible unilateral-oscillating perspective between instruments and subjectivity; we could say that the interrelationship is co-shaping and the rate speed of change is also proportionally shared.

To illustrate what Hegel's text explains, it is adequate to recall a previous testimony in the comprehension of our experience of the world through instruments of mediation. Particularly when a concrete instrument acts as well as an unveiling metaphor of the process of experience, precisely because it is the very notion of experience that acquires a new and rich meaning in the Phenomenology.

The device called camera obscura has been considered, more than once, as a metaphor to illustrate Descartes' horizon in observing the world ${ }^{2}$. This device becomes thus an example of instrumental embodiment of our inquiring contemplation of the external world, and by which it was also possible to emphasize the idea of an individual and intimate perspective of reality. The opinions, of course, are not unanimous. Some of them assume that, beyond the character of intimacy and individuality, it puts into evidence the narrow, distant and distorted access we have to the external world. So, the interposition of this "wooden box" between the world and us simply magnifies the fracture world-mind and the correspondent dualism and all the subsequent tragedies in all ambits, anthropological, epistemological, ethical, religious, and so forth. But a more attentive look ${ }^{3}$, could tell us something different: it rather emphasizes the structural continuity between the real world and the projection produced through the device; especially considering Descartes himself assuming God's point of view, from which he could evaluate the whole frame and declare that the animated reflected image, the light, the blank screen and the rest of the apparatus constitute a single entity. Then we realize there is a higher frame in which one systematizes the general event, and so the effort to integrate the camera to the "in-coming" reality should not be that of supernatural proportions. This means that the camera, the "captured" objects, and us, as observers, are all in the same world. And it is essential to acknowledge and affirm such continuity because the

2 BAILEY, Lee Worth, Skull's Darkroom: The Camera Obscura and Subjectivity, pp. 63-79. In DURBIN, Paul T., Philosophy of Technology. Practical, Historical and Other Dimensions, Kluwer AP, 1989, 191pp.

3 IHDE, Don, Art precedes science. In KOCKELKOREN, Petran (ed.), Mediated Vision, Veenman Publishers and ArtEZ Press, Rotterdam 2007. p. 30. 
camera obscura, as a metaphor for our own skull (the "skull's darkroom" as L. W. Bailey defines it) and its inner complexities, could help to understand in a different way the problem of sensible representations, restoring certain degree of reliability on the projected objects and the world, where the "outside" and "inside" are not unconnected but merged as dimensions of a continuous spatial relationship. It could be said here that the metaphor helps to better understand the unity between distinct realms than to make explicit a separation. In addition, for some critics the camera obscura was deemed as a way of cheating ${ }^{4}$, allowing underachiever artists to make copies of landscaping easily. From a different view it was a true new exploratory device with its own creative values; but what is not only interesting but also inspiring in terms of Hegelian thought is that some artists, already in the Renaissance, found challenging, and even a source of certain discouragement, the fact that one thing was beyond their possibilities to "retain" or capture in the blank surface: the image in motion. Such creative uneasiness might explain why the development of the camera obscura could be linked more specifically and adequately to photography and video filming than to realistic painting ${ }^{5}$. Scientific instruments for monitoring phenomena have eventually involved more senses than just sight or sound alone.

Analogously, an instrument that could illustrate the universe as contemplated by Hegel in Consciousness is the reflective telescope; such device reached a considerably high state of development precisely during Hegel's life span, and he was certainly not indifferent to the structural improvements of the instruments by which we sense things; for instance, he supported the idea that our considerations about the heavens must be adjusted according to new discoveries and observations of celestial bodies. Observing the wide and deep expanding development of instruments for the study of celestial bodies, following with the metaphor of the camera obscura, could be a good plastic expression where to observe the dialectic movement taking place within Consciousness. The telescope, in general, is a special case due to its diversified trajectory of development; it has traveled from the improvement of optical telescopes to radio telescope, and then to optical lenses plus digital imaging, as well as the combination of them and so on.

I would like to focus, metaphorically, on the specific principle under which the reflective telescope commonly works, which is in itself astounding: a microscope incorporated to a telescope where, interestingly, the incoming optic forces, our sight and the light of stars encounter each other in a mirrored

4 STEADMAN, Philip, Vermeer's Camera: uncovering the truth behind the masterpieces, Oxford University Press, 224pp. Concretely Chapter 1: The Camera Obscura, pp. 4-23.

5 FRIEDEL, Robert. A Culture of Improvement, Technology and the Western Millennium. The MIT Press. Cambridge MA 2007. 588pp. Cfr. p. 343. 
surface. Similarly to the camera obscura, this feature spontaneously brings forth the idea of an observational instrument located within a frontier but not a fracture; even a deep continuity between the micro and macro phenomena could be acknowledged through that idea. The telescope itself turns our attention to astronomy, in many ways the cradle of science and not only modern, a specific discipline that expresses how much our mind can stretch out in its attempt to reach the unknown. Cicero, in fact, used for the first time the term satellites applied to our senses, meaning they were messengers of the external world to our understanding ${ }^{6}$. Nicholas of Cusa also looked at the study of celestial bodies as an effort to acquire a standpoint wide enough to better understand totality, to understand the infinite in the finite ${ }^{7}$.

But, in this sense, the "tele + micro" metaphor is not here the one of highest value, or pertinence, as much as the specific general situation of the observer. After the amazement and awe before the contemplation of celestial bodies, a bit of reflection might well lead us to wonder: Where am I exactly looking at, what exactly am I looking into? And, more important, what was I really looking for?

To start, it could be said that we are looking into is a small mirror, to a tiny reflection of hard-to-imagine distant phenomena, precisely, of astronomical dimensions. But wait, there is more, no matter how much I want to "get into it" the object of my immediate approach is the image in the mirror, not the reflected object. Finally, if time and attention allow, I will eventually come to realize that, no matter how powerful or precise the observational instrument is, I rely on my sensible and rational faculties to access the phenomenon in question; so, every possible outcome of my observations rely on a twofold systematization, so to speak, the instrument and me, which adequately analyzed shows that the system as a whole is put to the test, questioned and revised. The interrelation is not superficial, mere external contact, for the instrument is already a space where I have transfered my desire to know and much of my capacity of perception; it is not only an extension of my sight, it crystallizes the inner need of expansion, of conquest of spirit, it is the embodiment of my inner outward impulse to know. And the relationship of embodiment its not static but dynamic, it is a living and co-shaping relationship. It is then impossible to think that while the

6 CICERO, M. T., De Legis, 1.I, VII, IX. "Ipsum autem hominem eadem natura no solum celeritate mentis ornavit, sed etiam sensus, tamquam satelites, attribuit, ac nuntios: et rerum plurimarum obscuras, nec satis enodatas intelligentias, quasi fundamenta quaedam scientiae".

7 Particularly chapters 1 and 5 of the first book of De docta ignorantia: "And you see how the unity of things, or the universe, exist in plurality and, conversely, how plurality exists in unity". NICHOLAS, De docta ignorantia, Book Two, Chapter One, n. 95-96. In NICHOLAS OF CUSA, Selected Spiritual Writings, Trad. H. Lawrence Bond, Paulist Press, New York 1997. 362pp.,p. 141. 
different instruments undergo deep and constant transformations my horizon of experience remains the same, it would be also naïve also to think that the telescopes have perfected themselves "alone"; the principle behind the modifications and improvement of such instruments is as complex as the one that concerns the evolution of living forms. Any observational instrument, ordinarily characterized as extensions of our senses, represents indeed the embodiment of our spirit's search to know; if we had a few millions of years, and no other thing to do, we could have just grown the telescope out of our eyeballs. Even more fascinating is the consideration that the different rates of speed motion that frames the change of instruments and human experience constitutes, in itself, the multidimensional response to the universe's dynamism speed-rate of change, to which they both are submitted.

Ordinarily, the change of scientific instruments often takes place in a particular space frame, fully developed in modernity: the laboratory, a working-place of dynamic co-shaping activities between instruments and human understanding. It is hard to find terms strong enough that may emphasize the dynamism of the activity developed there, though the basic idea of induction helps (it implies numerous experiments, creating constantly, over and over, the conditions to experience certain events), as adequate as Consciousness, in its particular way, does. For, what do we do at the lab? Experiments, constantly and systematically. But, as said before, where is the real laboratory? Where does the deep uneasiness that makes us doubt about what the apparatus "shows" or unhappy about what we see emerging from it? Where is the science that invents things born? Where do inventions, findings, exactly take place? Hegel's approach to these first early stages in developing a self-critical structure appears in Consciousness, in the first part of the Phenomenology. Consciousness represents the laboratory where the solution to the great question about solving the world begins. And it is important to note Hegel's tone of exposition throughout the segment, especially as it runs slow and up-hill all the way, because it constitutes in itself a resource to explain or, even better, to show the hardships of the complex and difficult path to Absolute Knowing and why perhaps it is somehow easy to remain in the very first stages, within a weak conception of experience.

As said previously, a richer and more fruitful characterization of experience springs forth from the Phenomenology's Consciousness, concretely in SenseCertainty. Experience is never a unilateral event. It is convergence of a wide plurality of elements, a multidimensional co-involvement. And the experience of every "new" object is essentially constituted by the transformation of the horizon of experience. Experience means, truly, a total, whole, inner and outer transformation, a true and proper reconfiguration (revolution) of the knowing structure. Any transformation of the object implies the reconfiguration of the structure of truth, the "truth structure", which is essentially dynamic. For Hegel, 
the inner movement of Consciousness is what really produces "experience"; that is, experience is a movement of consciousness itself reaching its peak in Force and Understanding.

But it is the first act of Consciousness, in the turning to the object, dwells what is essential for the concept of experience: the intention. This in-tendere is a qualitative orientation, the focusing on a specific ambit; following the metaphor, directing the telescope is merely a tangible expression of the beginning of science which abides in the constant capacity of wonder before the event of being, in remaining "open" to the gradual and interminable (un-exhaustive) emergence of the thing's richness, as Heidegger would later point out. But the "beginning", the origin, of knowledge is not then "in us" as something remaining within itself, it is a disposition of "listening" beyond; in accepting our poverty and acknowledging what things themselves can tell us about them and ourselves. It abides in an outward force, in a particular going out to see. Yet Consciousness shows how "seeing" is not enough: I must apprehend its object and also become, in some way, that object; here Hegel shows how this fantastic event starts as an awakening every time we find something, this something. Concerning our exploration of the world, along with Self-Consciousness, it can hardly be found another place in the Phenomenology where Hegel may emphasize more the character of incompleteness and insufficiency of every particular moment towards Absolute Knowing as in Consciousness.

Analogously, at some point, in the loneliness of the astronomical observatory or in the midst of all the paraphernalia of the laboratory (think about the "mega" Hadron Collider), the question comes out: why? Why we want to see, to know? And, what do we want to know? What is the real purpose? Any instrument or device into which we transfer any form of rationality, idea or operative capacity, can awake the same questions. Perhaps when, at the end, when there is nothing else to infuse into technologies, we might find that what truly distinguishes us from the rest of things and other forms of life (no matter how hard to define it is). But even in the case when we find really "nothing", hopefully we will know ourselves a little more, a little better. 
